\title{
Clinical perspectives of TRAIL: insights into central nervous system disorders
}

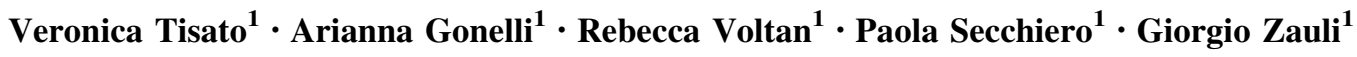

Received: 17 November 2015/Revised: 8 February 2016/ Accepted: 9 February 2016/Published online: 24 February 2016

(C) The Author(s) 2016. This article is published with open access at Springerlink.com

\begin{abstract}
The TNF-related apoptosis inducing ligand TRAIL is a member of the TNF superfamily that has been firstly studied and evaluated for its anti-cancer activity, and the insights into its biology have already led to the identification of several TRAIL-based anticancer strategies with strong clinical therapeutic potentials. Nonetheless, the TRAIL system is far more complex and it can lead to a wider range of biological effects other than the ability of inducing apoptosis in cancer cells. By virtue of the different receptors and the different signalling pathways involved, TRAIL plays indeed a role in the regulation of different processes of the innate and adaptive immune system and this feature makes it an intriguing molecule under consideration in the development/progression/treatment of several immunological disorders. In this context, central nervous system represents a peculiar anatomic site where, despite its "status" of immune-privileged site, both innate and adaptive inflammatory responses occur and are involved in several pathological conditions. A number of studies have evaluated the role of TRAIL and of TRAILrelated pathways as pro-inflammatory or protective stimuli, depending on the specific pathological condition, confirming a twofold nature of this molecule. In this light, the aim of this review is to summarize the main preclinical evidences of the potential/involvement of TRAIL molecule and TRAIL pathways for the treatment of central nervous system disorders and the key suggestions coming from
\end{abstract}

Veronica Tisato

veronica.tisato@unife.it

1 Department of Morphology, Surgery and Experimental Medicine and LTTA Centre, University of Ferrara, Via Fossato di Mortara 66, 44121 Ferrara, Italy their assessment in preclinical models as proof of concept for future clinical studies.

Keywords TRAIL · Neuroinflammation ·

Alzheimer's disease · Multiple sclerosis · Ischemic stroke · Therapeutic potential $\cdot$ Biomarker

\section{Introduction}

The acronym TRAIL designates a member of the tumor necrosis factor (TNF) family first reported in the 1990s by two independent studies. Both described TRAIL, TNF-related apoptosis-inducing ligand, as a protein able to mediate cell signals triggering caspase activation and programmed cell death in several cell types $[1,2]$. Although interest in its biological features has primarily been focused on its anti-cancer activity [3-7], growing attention is also being paid to TRAIL involvement in both normal immunological homeostasis, and the development/monitoring of pathological conditions, by virtue of its involvement in different processes of the innate and adaptive immune systems. In this light, our group has extensively contributed to demonstrate an inverse correlation between the circulating levels of TRAIL and the chronic inflammation present in several pathological settings, suggesting that TRAIL may have potential as a biomarker. We have also shown that low levels of TRAIL are associated with total and cardiovascular mortality in older adults and interestingly, we have demonstrated that $17-\beta$ estradiol could play a role in regulating the amount of TRAIL in circulation by mediating downregulation of TRAIL expression [8, 9]. In addition, and in line with other reports, we have shown that TRAIL is inversely associated with outcome and mortality in patients with several 
pathological conditions, which include chronic kidney diseases, heart/kidney transplant, and cardiovascular disorders such as acute myocardial infarction, heart failure, and coronary heart disease [10-15]. More recently, clinical studies have shown significant changes in the circulating levels of TRAIL in patients affected by Type $1[16,17]$ and Type $2[18,19]$ diabetes mellitus [20], confirming the results of previous in vitro and in vivo preclinical studies that suggested a general protective effect of TRAIL in the development/progression of diabetes and diabetes-related complications [21-24].

However, the role of TRAIL seems to be fairly ambiguous, with different reports suggesting conflicting roles for TRAIL in the development/control of several pathological conditions. This apparently paradoxical behavior has recently been highlighted and reviewed on rheumatoid arthritis [25], for example, in which some reports implicate TRAIL in its pathogenesis, while others suggest it may have a protective effect, potentially by controlling synovial hyperplasia and immune cell hyperactivation and acting as a prognostic factor [25, 26]. A possible protective role of TRAIL has also emerged from preclinical [27] and clinical studies in atherogenesis [28], which seem to indicate that TRAIL acts to control homeostasis in atherosclerotic blood vessels. However, there may also be a harmful relationship between levels of TRAIL and vascular inflammation and atherosclerosis, and this requires further investigation [29]. Similarly, while some authors report a potential involvement of endogenous TRAIL in the development of allergic asthma in preclinical models [30], we, among others, have shown that soluble exogenous TRAIL appears to play a protective role in the resolution phase of asthma in a model of chronic allergen inhalation [31, 32].

It appears therefore that the activities and functions of TRAIL are extremely complex, being the result of the involvement of multiple pathways and of multiple levels of control, with each depending upon the specific cell type and the specific biological/pathological context. Hence, discovering the interplay between resident and immune cells may be the key to understanding the development of several diseases, and could lead to the identification of new therapeutic targets. Under normal conditions the central nervous system (CNS) has a so-called "immune privilege status" characterized by limited local inflammation. However, in presence of pathological disorders like Alzheimer's disease, multiple sclerosis and local brain injuries such as ischemic stroke, which all share common features [33], immune responses are stimulated via activation of microglia and infiltration of circulating cells [34, 35]. In order to shed light on the involvement of TRAIL in this process, starting from our experience and knowledge of the role of TRAIL in different pathological settings, we set out to review the state of the art on the role of TRAIL in the CNS.

\section{TRAIL and TRAIL-mediated signalling}

The TRAIL protein is encoded by a gene mapped on chromosome 3 at position 3q26. This site spans approximately $20 \mathrm{~kb}$, includes five exons and four introns, and is regulated by a combination of factors, including transcription factors, epigenetics factors, and the presence of single-nucleotide polymorphisms and functionally distinct isoforms [36, 37]. Like other members of the TNF family, TRAIL protein can be detected as trans-membrane type protein and as soluble protein [38]. TRAIL exerts its biological effects through interactions with a complex ligandreceptor system of five cognate receptors, which can be bound with different affinities under normal physiological conditions [39, 40]. In humans, TRAIL is released by several cell types, and is capable of binding the transmembrane pro-apoptotic death receptors TRAIL-R1/DR4 and TRAIL-R2/DR5. It also binds to the two transmembrane decoy receptors TRAIL-R3/DcR1 and TRAIL-R4/ DcR2, which lack an intact death domain. The fifth element of the TRAIL receptor system is osteoprotegerin (OPG), originally discovered as a mediator of osteoclastogenesis regulation via interaction with the receptor activator of NFKB ligand (RANKL) [41-47]. OPG is a secreted protein that lacks both transmembrane and cytoplasmic domains; it is able to bind not only RANKL, but also TRAIL, for which it acts as a soluble neutralizing receptor [3]. Interestingly, mice, unlike humans, only have one TRAIL receptor containing a death domain DD (mDR5); this, however, does show $60 \%$ sequence homology with human DR4 and DR5 [1]. Mice also have the two decoy receptors, mDcR1 and mDcR2, that correspond to human decoy TRAIL receptors DcR1 and DcR2, albeit with differences in sequence structures. These findings suggest that TRAIL decoy receptors are a relatively recent evolutionary event [48].

As previously mentioned, the best characterized biological function of TRAIL is its ability to induce apoptosis in various cancer cells types [49-51]. This is mediated by its two death-domain-containing receptors, whereas TRAIL-DcR1, TRAIL-DcR2 and OPG are considered neutralizing or regulatory receptors [52]. Signals resulting from death-domain-ligand interaction can induce apoptosis via assembly of the death-inducing signalling complex (DISC) [53]. This is formed by the Fas-associated death domain (FADD), which promotes autocatalytic processing of caspases, activation of caspases, and thereby apoptosis [53].

Two TRAIL-activated death pathways have been identified, an extrinsically mediated death pathway, found in 
cells generating enough caspase-8 (or -10) activation and apoptotic signalling to promote cell death, and a second death pathway in cells that require additional processes to lead to full apoptosis through cleavage of the pro-apoptotic protein BH3 interacting-domain (Bid) (Fig. 1). However, TRAIL can also activate other signal transduction pathways [53]. The binding of TRAIL to its cognate receptors can promote non-apoptotic, pro-survival and proliferation signals through several intracellular molecular mediators, including the transcription factor nuclear factor- $\mathrm{\kappa B}$ (NF$\kappa \mathrm{B})$, the mitogen-activated protein kinases (MAPKs), and PI3K/Akt and ERK pathways, and ultimately leading to transcription of survival genes able to regulate developmental and inflammatory processes (Fig. 1) [54, 55]. For initiation, such pathways rely on the recruitment of adaptor molecules such as TNF-receptor-associated death domain protein (TRADD), TNF-receptor-associated factor-2 (TRAF2), receptor interacting protein (RIP1), and apoptosis inhibitor proteins, which assemble into a complex that mediates intracellular signal transmission (Fig. 1).

The "cell selectivity" of TRAIL in inducing apoptosis is directed towards transformed/infected cells, leaving nontumor cells largely unaffected, and has therefore been the focus of much scientific interest. However, increasing experimental evidence suggests that TRAIL might have several alternative roles in normal cells/tissues. Our group has already shown that TRAIL promotes the survival/proliferation of endothelial cells, suggesting that the TRAIL/
TRAIL-R system plays an important role in endothelial cell physiology and the biology of the vascular system [56], and affects the survival, migration and proliferation of vascular smooth muscle cells through activation of specific intracellular pathways [57]. TRAIL can also promote prosurvival/proliferative effects and interfere with differentiation processes in several other cell types, including multipotent stem cells, osteoclasts, myeloid cells and intestinal cells [58-63], and can even, paradoxically, activate pro-survival pathways in sensitive neoplastic cells [55]. These contrasting biological effects (proliferation/survival versus apoptosis) seem to depend on the type of cells involved, and remains one of the most fascinating features of TRAIL biology.

In this regard, one hypothesis considers the different cell-related susceptibility to TRAIL as the result of different patterns of TRAIL receptors expression, specifically a different ratio between pro-apoptotic (DR) and decoy (DcR) receptors [54, 64]. The concept of "lipid rafts" has been introduced to describe plasma membrane platforms involved in mediate death receptor signals [65]. Structurally, these are dynamic pools rich in cholesterol and sphingolipids. They are able to trigger TRAIL-DISC-initiated intracellular apoptotic signals, and some reports suggest that a redistribution of TRAIL receptors and DISC composition from "non rafts" to "lipid rafts" could explain the switching between proliferative/survival and apoptotic TRAIL-mediated cell pathways in different cellular
Fig. 1 Schematic representation of TRAIL signalling pathways. The picture is a schematic representation of the main molecular mediators involved in the TRAILmediated apoptosis (both intrinsic and extrinsic pathways) and TRAIL-mediated cell survival, induced by the interaction between TRAIL and its receptors. On the upper panel, a schematic representation of the five cognate TRAIL receptors is shown. DcR1 and DcR2 are decoy receptors for TRAIL as well as the soluble osteoprotegerin

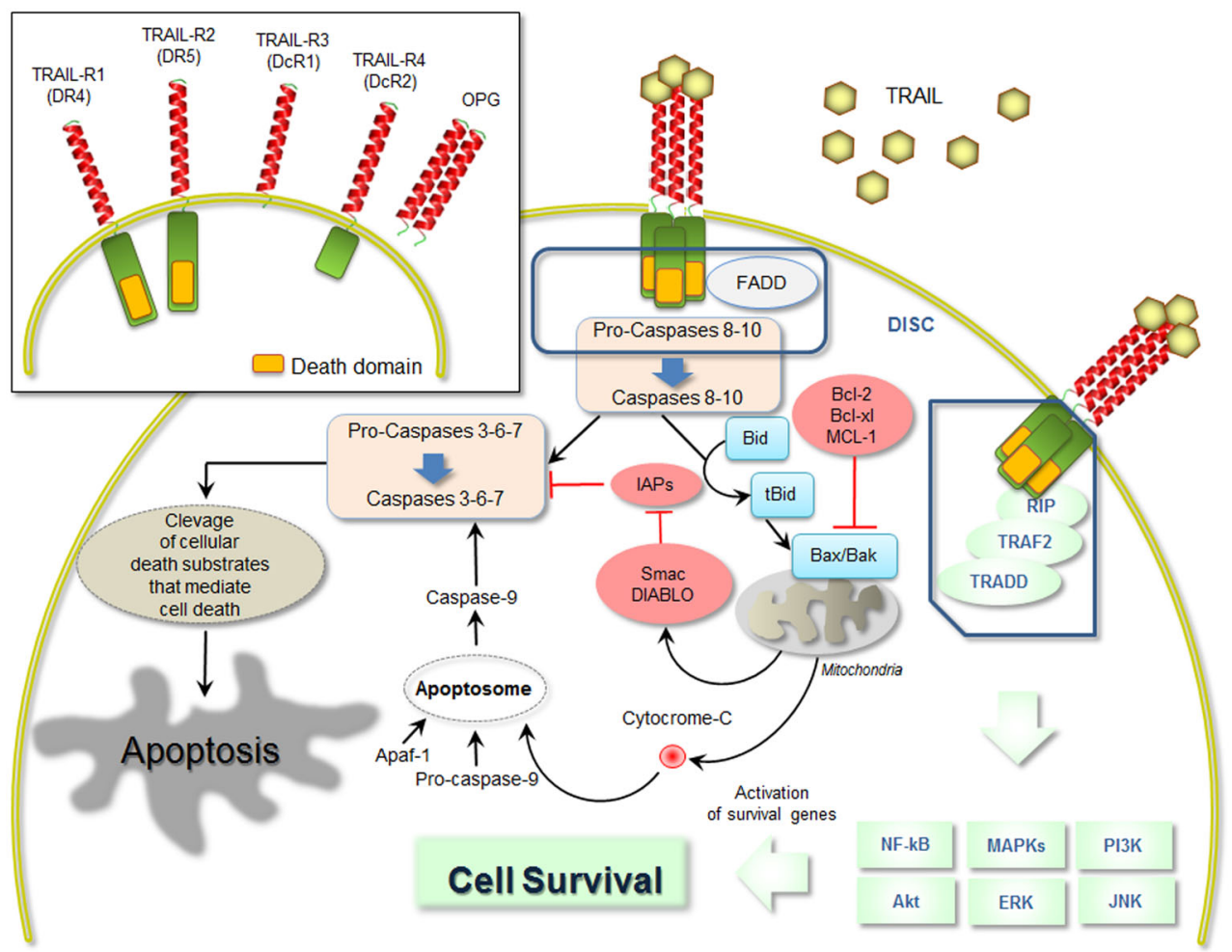


contexts [65-68]. Unsurprisingly, both the role and distribution of TRAIL receptors and the ratio between DR and DcR are still under debate and evaluation [69, 70].

The expression of TRAIL/TRAIL receptors in the brain has been analyzed by two independent groups, finding that the cytokine is virtually absent in healthy tissue, with only low levels of TRAIL ligand expression on oligodendrocytes [71, 72]. Nevertheless, both groups found similar DR4 and DR5 expression profiles, but some differences in patterns of expression of decoy receptors [71, 72]. In particular, Cannella et al. reported oligodendrocytes and neurons as the main cells expressing DcR1, and microglia the main cells expressing DcR2, while Dorr and colleagues reported that DcR1 and DcR2 were predominantly expressed by neurons and oligodendrocytes/neurons, respectively [71, 72]. This different pattern of expression of the components of the TRAIL-system in the CNS, differentially regulated in the presence of a local disease, suggest the presence of TRAIL-mediated mechanisms in the CNS. Moreover, evidence that brain tissue is susceptible to TRAIL-induced apoptosis [73] raises the hypothesis of a potential dual role of TRAIL in the CNS: on one hand leading to the activation of apoptotic pathways behind cell damage and disease progression, and on the other an overall protective/pro-survival effect, supporting the manipulation of the TRAIL system for therapeutic purposes [74].

\section{Perspectives of TRAIL in Alzheimer's disease}

Alzheimer's disease (AD) is an irreversible, progressive degenerative disorder that leads to gradual cognitive impairment characterized by memory loss, reduction of intellectual abilities, changes in personality and behavior, and onset of dementia [75]. Occurring in hereditary and sporadic forms, the clinical features of $\mathrm{AD}$ are the result of the gradual malfunctioning and death of neurons, mainly in the cortex and hippocampus, due to accumulation of extracellular amyloid plaques and intracellular neurofibrillary tangles $[75,76]$. Inflammatory processes are also involved in the pathological progression of the disease, and may even be the cause or driving force behind it [77]. In this regard, TRAIL is specifically expressed in the brains of AD patients, which display a TRAIL-specific immunoreactivity mainly localized in AD-affected regions, such as the cerebral cortex, often in the proximity of Congo-redpositive amyloid plaques [78]. Furthermore, preclinical in vitro cellular models have implicated TRAIL in the betaamyloid protein-dependent cell death known to contribute to the neurodegenerative process and associated chronic inflammation characteristic of AD [79]. Indeed, specific blockade of the TRAIL death receptor DR5 has been shown to completely prevent amyloid beta-related neurotoxicity in two cellular models, a neuronal cell line and primary cortical neurons, suggesting a key role for DR5 in the TRAIL-induced death pathway in AD [80]. Moreover, the vascular deposition of amyloid beta, which alters cerebral blood flow and thereby contributes to cognitive impairment in AD seems to be mediated by DR4 and DR5 death receptors, via both caspase-8- and caspase-9triggered apoptotic pathways in human cerebral microvascular endothelial cells [81].

More recently, the role of TRAIL as a mediator of amyloid-beta neurotoxicity has been explored as a potential therapeutic target for the treatment of $\mathrm{AD}$ in a triple transgenic mouse model of $\mathrm{AD}$ [82]. In their work Cantarella and colleagues have demonstrated that blocking TRAIL release and activation of apoptotic TRAIL receptors by means of a neutralizing monoclonal antibody can attenuate amyloid-beta-induced neurotoxicity [82]. In particular, treatment via intraperitoneal infusion started 6 months before the onset of the disease led to reduced amyloid-beta deposition, functional improvement, and a reduction in the inflammatory response in the brain, resulting in a significant overall improvement in cognitive parameters [82].

Evidence that there is no difference in circulating levels of TRAIL between AD patients and healthy controls seems to suggest that this effect is local and restricted to the CNS [83]. It may be that TRAIL is released by neurons in response to local stress generated by the accumulation of oligomers of amyloid-beta. Alternatively, it could be released by infiltrating immune cells or other cell types reacting to amyloid- $\beta$ oligomers or increased neuronal signals [84]. Although several aspects of this approach evidently still need to be refined, this can nevertheless be considered a proof of concept that targeting amyloid pathology via manipulation of TRAIL pathways may be a new therapeutic approach for the clinical management of $\mathrm{AD}$ patients.

\section{Perspectives of TRAIL in multiple sclerosis and secondary cognitive impairment}

Multiple sclerosis (MS) is a demyelinating disease of the central nervous system, and primarily the result of an autoinflammatory reaction, although genetic predisposition and environmental factors may be implicated [85] and it still represents one of the major causes of chronic neurological disability. Even though its own etiology remains unclear, it is known, however, that the major feature of the disease is the disruption of the myelinated tracts of the CNS by autoreactive lymphocytes [86]. This leads to cumulative and irreversible damage, as well as progressive disability [86]. In its early stages, this pathological cascade appears to be driven by a peripheral immune response targeting the CNS, 
followed by a later progressive phase characterized by local immune reactions within the CNS [87]. According to a recent review of the state of the art in MS, the main processes leading to neurodegeneration include microglia activation, chronic oxidative injury, accumulation of mitochondrial damage in axons, and age-related iron accumulation in the human brain [88].

Research in the field of MS takes advantage of the availability of murine models of the disease, including experimental autoimmune encephalomyelitis (EAE), providing insights into the biological processes and development/progression of MS [89]. Although no single model can replicate the complexity of MS and all its pathogenic pathways [89], preclinical evidences show that blockade of the TRAIL-pathway in mice by various approaches exacerbated EAE, increasing both disease score and the degree of inflammation in the CNS, while treatment with recombinant soluble TRAIL delayed disease onset and reduced the severity of EAE [90, 91]. It appears that TRAIL-mediated effects were not related to apoptosis induction in inflammatory cells, but rather to the prevention of autoreactive $\mathrm{T}$ cell activation [90-92]. In addition to its influence on $\mathrm{T}$ cell growth/functionality, there is evidence that TRAIL is involved in triggering and promoting $\mathrm{CD}^{+}{ }^{+} \mathrm{CD} 25^{+}$regulatory $\mathrm{T}$ cells [93]. Nevertheless, a TRAIL-mediated contribution to cell damage in the CNS in the presence of neuroinflammation has also been reported [94], confirming that this molecule has a dual role, provoking different outcomes when peripheral or central tissues are involved and inducing contrasting effects at different stages in the course of the disease. It is evident that these two "sides" of TRAIL, anti-inflammatory and proapoptotic, could be targeted differently for the same therapeutic purpose in EAE/MS, and, indeed, the therapeutic potential of targeting the TRAIL system to manage EAE has recently been explored using different approaches. In one study, a fusion protein between the extracellular domain of fibroblast growth-factor-inducible 14, formally the cell surface receptor for the TNF family member inducer of apoptosis TWEAK, and the extracellular domain of TRAIL was designed as an anti-inflammatory agent [95]. Injected daily at different time points after disease induction in mice, the fusion protein brought about clinical improvement correlated with: (1) decreasing lymphocyte infiltrate in the CNS; (2) decreased Th1/Th17 responses, and (3) increased number of regulatory T cells [95]. Similarly, prior to the onset of EAE, intrathecal delivery of a plasmid DNA coding for a fusion protein between TRAIL and OX40, a member of the TNF receptor super family predominantly expressed on activated $\mathrm{T}$ cells, reduced disease severity and inflammatory cell infiltrates [96].

As higher TRAIL levels have been reported in established MS lesions [71, 72], and affected brains show a different pattern of death receptor expression than healthy controls, the TRAIL system could play an important role in the pathological process of MS [71, 72]. In the light of the body of evidence coming from preclinical EAE model, attention has turned to TRAIL as a potential clinical biomarker in MS, focusing also on the possible link between gene polymorphisms of TRAIL system components and the clinical course of the disease. Although a recent study reported no difference in serum TRAIL levels between MS patients and healthy controls, comparative analysis of patients reporting different clinical forms and activity phases of the disease showed that TRAIL is significantly reduced during relapse in relapsing-remitting MS patients [97]. In the same context, other authors have reported lower serum levels of soluble TRAIL protein in MS patients with respect to healthy controls but they found no differences in the expression ratio of the TRAIL mRNA gene expression ratio [98].

These discrepancies suggest the need for larger cohort of patients and appropriate functional studies, in particular to investigate whether the TRAIL levels observed in MS patients are associated with enhanced survival of pathogenic $\mathrm{T}$ lymphocytes and other inflammatory markers. Moreover, since TRAIL has been suggested to be involved in Interferon beta (IFN- $\beta$ ) activity, the assessment of its expression has been proposed as potential prognostic marker of treatment response to IFN- $\beta$ in MS patients [99, 100]. Other lines of evidence suggest that genetic variants of the TRAIL and TRAIL-receptor genes may be associated with MS susceptibility as reported by studies considering different single-nucleotide polymorphisms and splice variants in different cohorts of patients [101-103]. However, larger sample sizes are required to confirm the preliminary results indicating that splice variants of the TRAIL system could have a potential as predictors of IFN$\beta$ treatment in MS patients [104].

The role of TRAIL has also been evaluated in other cognitive impairment conditions, often secondary manifestations of specific primary diseases such as viral infection, or the result of distress related to depression or drug use. For instance, despite considerable advances in treatment, neurocognitive impairment still occurs in HIVinfected subjects, whether asymptomatic, mild neurocognitive disorder or HIV-associated dementia (HAD) [105]. This may be due to the virus infecting the perivascular macrophages and microglia in the brain and the release of viral proteins that directly kill neurons [105], or inflammation and neuron loss may be ascribable to inflammatory mediators released from the macrophages and microglia activated in response to HIV infection [105]. In the context of HAD, TRAIL has been shown to actively participate in neuron loss [106] by inducing apoptosis in HIV-1-infected macrophages and cultured neurons [106]. TRAIL levels are 
increased in human monocyte-derived macrophages after HIV-1 infection and it is known to be mediated by IRF-1, IRF-7, Type-I IFNs, and STAT-1 [107].

In psychiatric disorders, which are associated with neuroendocrine changes, a recent study has evaluated the pattern of expression of circulating cytokines in the search for potential biomarkers [108]. The results show that 13 cytokines, including TRAIL-R4, are overexpressed in individuals with major depressive disorder reporting childhood trauma, suggesting a relationship between depression and cytokine alterations [108]. Moreover, in line with the evidence that drug abuse affects the inflammatory system, another recent study has analyzed the plasma levels of soluble receptors/ligands in cocaine-dependent subjects experiencing or not early life stress in comparison with control subjects [109]. TRAIL levels were higher in cocaine-dependent subjects experiencing early life stress, which, although failing to reach statistical significance, does indicate a possible link with circulating levels of pro-inflammatory mediators [109].

\section{Perspectives of TRAIL in ischemic stroke}

Ischemic stroke results in a cascade of events involving neuronal death, alteration of the white matter pathophysiology, and local inflammation. The resulting clinical picture is so complex that, while trials testing a preventive approach have gained major successes in recent years, the search for effective acute stroke treatments has encountered many failures. This suggests that successful translation of biological/pathophysiological knowledge into effective clinical approaches will definitely require an integrative approach [110]. In particular, the cerebral inflammation, the biological significance of its resolution, and the repair of neuronal damage, have been recently reviewed focusing in particular on the role of the so-called DAMPs, i.e., molecules released from damaged cells that play a key role in triggering local inflammation [111]. During ischemic stroke, activation of the microglia is followed by local recruitment of leukocytes to the brain lesion, thereby contributing to the tissue injury pathogenesis [112-114]. In this context, TRAIL seems to play a role in inducing apoptosis, as evidenced in preclinical models $[115,116]$ that highlight the involvement of TRAIL in neuronal apoptosis in vivo after ischemia. This apparently occurs through a c-Jun-mediated signalling pathway that was completely prevented by immunosuppressant treatment [115].

In a murine model of global cerebral ischemia, expression and upregulation of both TRAIL and its receptor DR5 have been shown after transient ischemia-reperfusion [117]. Expression of TRAIL was more selective to astrocytes and activated microglia/macrophages, while the DR5 receptor was more predominantly expressed in neurons [117]. In the same model, functionally inhibiting TRAIL by blocking its interaction with DR5 led to reduced apoptosis and a neuroprotective effect overall [117]. Other recent studies have confirmed the overexpression of TRAIL and TRAIL receptors in hypoxic brain [118, 119], and the local expression of decoy receptors for TRAIL has been shown to confer neuronal protection against lethal ischemia after ischemic preconditioning [120]. In particular, Cantarella and colleagues have shown that TRAIL is upregulated in focal ischemia, while it appears to be downregulated in sub-lethal brain ischemia and brains subjected to preconditioning stimulus [119]. In this model, neuroprotection elicited by ischemic preconditioning was found to occur through both upregulation of TRAIL decoy receptors and downregulation of its death receptors, as well as TRAIL itself, which indicated that TRAIL inhibition may significantly limit tissue damage and promote functional recovery [119].

Recent clinical trials have assessed TRAIL as a potential biomarker for acute stroke and stroke subtypes. However, a study performed in plasma samples of patients with recent lacunar infarcts (silent brain infarcts) revealed no significant difference in TRAIL levels with respect to healthy controls [121]. Nonetheless, in a recently published study performed in a cohort of patients with acute ischemic stroke, significant negative correlations between serum TRAIL levels and both clinical score and stroke volume have been reported, with no difference between the various stroke subtypes analysed, in line with findings reported in other cardiovascular diseases [122].

\section{Concluding remarks}

In line with findings obtained in other inflammatory conditions, the overall message from the recently published results is that TRAIL also plays a dual role in inflammatory disorders of the CNS, likely as the result of different involvement/effects of TRAIL pathway in local and peripheral inflammatory processes. In terms of future clinical perspectives, therefore, TRAIL appears to be an attractive therapeutic target, and TRAIL-based approaches interfering with TRAIL pathways have already demonstrated therapeutic potential, particularly in Alzheimer's disease and EAE/MS (Fig. 2). Moreover, preliminary evidence seems to suggest a potential role of circulating TRAIL as a biomarker for CNS-related disorders such as neurocognitive impairment and depression. Nevertheless, further investigation is required in order to: (1) clarify the local molecular insights into the mechanisms of action of TRAIL; (2) evaluate possible TRAIL-based treatment strategies, taking opportunely into account the different and 
Fig. 2 Snapshot of the main preclinical evidences of the involvement of TRAIL in neuroinflammatory diseases. The picture shows some of the most interesting features coming from the preclinical models/evaluations about the role of TRAIL in the context of Alzheimer's disease, multiple sclerosis and ischemic stroke in view of a future clinical development of TRAIL-based therapeutic strategies

\section{Alzheimer's disease}

- TRAIL is expressed in AD brain tissue

- In in vitro models, neuronal cells exposed to $A \beta$ amyloid express components of the TRAL system and undergo apoptosis

- In in vitro models, blockade of DR5 prevents amyloid beta-related neurotoxicity

- In in vivo model of $A D$ the blocking of TRAIL pathway is able to attenuate $A \beta$-induced neurotoxicity

\section{Multiple Sclerosis/EAE}

- DR4-DR5/TRAIL interaction induces brain cell death in EAE

- TRAlL-induced apoptosis of neurons contribute to neuronflammation

- Blocking TRAIL-pathway at local level attenuate the severity of the disease

- Therapeutic treatment with soluble TRAIL also reduces the severity of EAE

- Correlations between TRAIL levels/genetic variants of the TRAIL system have been correlated to MS susceptibility and INF- $\beta$ treatment

\section{(1)}

Ischemic stroke

- In in vivo models, TRAIL and DR5 were expressed and upregulated following transient ischemia-reperfusion

- In in vivo models, the inhibition of TRAlL functionality by blocking its interaction with DR5 or by expression of decoy receptors led to a reduced apoptosis and neuroprotective effect

- Negative correlations between serum TRAIL levels and clinical score and stroke volume of patients has been reported complex immunological features of the specific neurological disorders; and (3) develop appropriate delivery systems for both systemic and local approaches based on the specific molecular/clinical features of the diseases in question.

Open Access This article is distributed under the terms of the Creative Commons Attribution 4.0 International License (http:// creativecommons.org/licenses/by/4.0/), which permits unrestricted use, distribution, and reproduction in any medium, provided you give appropriate credit to the original author(s) and the source, provide a link to the Creative Commons license, and indicate if changes were made.

\section{References}

1. Wiley SR, Schooley K, Smolak PJ, Din WS, Huang CP, Nicholl JK, Sutherland GR, Smith TD, Rauch C, Smith CA et al (1995) Identification and characterization of a new member of the TNF family that induces apoptosis. Immunity 3(6):673-682

2. Pitti RM, Marsters SA, Ruppert S, Donahue CJ, Moore A, Ashkenazi A (1996) Induction of apoptosis by Apo-2 ligand, a new member of the tumor necrosis factor cytokine family. J Biol Chem 271(22):12687-12690

3. Zauli G, Secchiero P (2006) The role of the TRAIL/TRAIL receptors system in hematopoiesis and endothelial cell biology. Cytokine Growth Factor Rev 17(4):245-257. doi:10.1016/j. cytogfr.2006.04.002

4. Secchiero P, Zauli G (2008) Tumor-necrosis-factor-related apoptosis-inducing ligand and the regulation of hematopoiesis. Curr Opin Hematol 15(1):42-48. doi:10.1097/MOH.0b013e328 2f15fa6
5. Stuckey DW, Shah K (2013) TRAIL on trial: preclinical advances in cancer therapy. Trends Mol Med 19(11):685-694. doi:10.1016/j.molmed.2013.08.007

6. Gasparini C, Vecchi Brumatti L, Monasta L, Zauli G (2013) TRAIL-based therapeutic approaches for the treatment of pediatric malignancies. Curr Med Chem 20(17):2254-2271

7. Lemke J, von Karstedt S, Zinngrebe J, Walczak H (2014) Getting TRAIL back on track for cancer therapy. Cell Death Differ 21(9):1350-1364. doi:10.1038/cdd.2014.81

8. Volpato S, Ferrucci L, Secchiero P, Corallini F, Zuliani G, Fellin R, Guralnik JM, Bandinelli S, Zauli G (2011) Association of tumor necrosis factor-related apoptosis-inducing ligand with total and cardiovascular mortality in older adults. Atherosclerosis 215(2):452-458. doi:10.1016/j.atherosclerosis.2010.11.004

9. Zauli G, Tisato V, Melloni E, Volpato S, Cervellati C, Bonaccorsi G, Radillo O, Marci R, Secchiero P (2014) Inverse correlation between circulating levels of TNF-related apoptosisinducing ligand and 17beta-estradiol. J Clin Endocrinol Metab 99(4):E659-E664. doi:10.1210/jc.2013-4193

10. Niessner A, Hohensinner PJ, Rychli K, Neuhold S, Zorn G, Richter B, Hulsmann M, Berger R, Mortl D, Huber K, Wojta J, Pacher R (2009) Prognostic value of apoptosis markers in advanced heart failure patients. Eur Heart J 30(7):789-796. doi:10.1093/eurheartj/ehp004

11. Liabeuf S, Barreto DV, Barreto FC, Chasseraud M, Brazier M, Choukroun G, Kamel S, Massy ZA (2010) The circulating soluble TRAIL is a negative marker for inflammation inversely associated with the mortality risk in chronic kidney disease patients. Nephrol Dial Transplant 25(8):2596-2602. doi:10. 1093/ndt/gfq042

12. Secchiero P, Corallini F, Beltrami AP, Ceconi C, Bonasia V, Di Chiara A, Ferrari R, Zauli G (2010) An imbalanced OPG/ TRAIL ratio is associated to severe acute myocardial infarction. Atherosclerosis 210(1):274-277. doi:10.1016/j.atherosclerosis. 2009.11.005 
13. Secchiero P, Corallini F, Ceconi C, Parrinello G, Volpato S, Ferrari R, Zauli G (2009) Potential prognostic significance of decreased serum levels of TRAIL after acute myocardial infarction. PLoS One 4(2):e4442. doi:10.1371/journal.pone. 0004442

14. Osmancik P, Teringova E, Tousek P, Paulu P, Widimsky P (2013) Prognostic value of TNF-related apoptosis inducing ligand (TRAIL) in acute coronary syndrome patients. PLoS One 8(2):e53860. doi:10.1371/journal.pone.0053860

15. Brombo G, Volpato S, Secchiero P, Passaro A, Bosi C, Zuliani G, Zauli G (2013) Association of soluble tumor necrosis factorrelated apoptosis-inducing ligand (TRAIL) with central adiposity and low-density lipoprotein cholesterol. PLoS One 8(3):e58225. doi:10.1371/journal.pone.0058225

16. Tornese G, Iafusco D, Monasta L, Agnoletto C, Tisato V, Ventura A, Zauli G, Secchiero P (2014) The levels of circulating TRAIL at the onset of type 1 diabetes are markedly decreased in patients with ketoacidosis and with the highest insulin requirement. Acta Diabetol 51(2):239-246. doi:10.1007/s00592-0130507-5

17. Tornese G, Tisato V, Monasta L, Vecchi Brumatti L, Zauli G, Secchiero P (2015) Serum TRAIL levels increase shortly after insulin therapy and metabolic stabilization in children with type 1 diabetes mellitus. Acta Diabetol. doi:10.1007/s00592-0150731-2

18. Bisgin A, Yalcin AD, Gorczynski RM (2012) Circulating soluble tumor necrosis factor related apoptosis inducing-ligand (TRAIL) is decreased in type-2 newly diagnosed, non-drug using diabetic patients. Diabetes Res Clin Pract 96(3):e84-e86. doi:10.1016/j.diabres.2012.02.028

19. Xiang G, Zhang J, Ling Y, Zhao L (2014) Circulating level of TRAIL concentration is positively associated with endothelial function and increased by diabetic therapy in the newly diagnosed type 2 diabetic patients. Clin Endocrinol (Oxf) 80(2):228-234. doi:10.1111/cen.12312

20. Zauli G (2014) Circulating levels of TNF-related apoptosis inducing ligand (TRAIL). Clin Endocrinol (Oxf) 80(2):182-183. doi:10.1111/cen.12340

21. Zauli G, Toffoli B, di Iasio MG, Celeghini C, Fabris B, Secchiero P (2010) Treatment with recombinant tumor necrosis factor-related apoptosis-inducing ligand alleviates the severity of streptozotocin-induced diabetes. Diabetes 59(5):1261-1265. doi:10.2337/db09-1771

22. Secchiero P, Perri P, Melloni E, Martini A, Lamberti G, Sebastiani A, Zauli G (2011) Decreased levels of soluble TNFrelated apoptosis-inducing ligand (TRAIL) in the conjunctival sac fluid of patients with diabetes affected by proliferative retinopathy. Diabet Med 28(10):1277-1278. doi:10.1111/j.14645491.2010.03202.x

23. Perri P, Zauli G, Gonelli A, Milani D, Celeghini C, Lamberti G, Secchiero P (2015) TNF-related apoptosis inducing ligand in ocular cancers and ocular diabetic complications. Biomed Res Int 2015:424019. doi:10.1155/2015/424019

24. Bossi F, Bernardi S, Zauli G, Secchiero P, Fabris B (2015) TRAIL modulates the immune system and protects against the development of diabetes. J Immunol Res 2015:680749. doi:10. 1155/2015/680749

25. Audo R, Combe B, Hahne M, Morel J (2013) The two directions of TNF-related apoptosis-inducing ligand in rheumatoid arthritis. Cytokine 63(2):81-90. doi:10.1016/j.cyto.2013.04.011

26. Audo R, Daien C, Papon L, Lukas C, Vittecoq O, Hahne M, Combe B, Morel J (2015) Osteoprotegerin and tumor necrosis factor-related apoptosis-inducing ligand as prognostic factors in rheumatoid arthritis: results from the ESPOIR cohort. Arthr Res Ther 17:193. doi:10.1186/s13075-015-0705-3
27. Di Bartolo BA, Chan J, Bennett MR, Cartland S, Bao S, Tuch BE, Kavurma MM (2011) TNF-related apoptosis-inducing ligand (TRAIL) protects against diabetes and atherosclerosis in Apoe (-)/(-) mice. Diabetologia 54(12):3157-3167. doi:10. 1007/s00125-011-2308-0

28. Secchiero P, Zauli G (2012) TRAIL, a new weapon against neointimal hyperplasia. Cardiology 123(2):94-96. doi:10.1159/ 000342983

29. Cheng W, Zhao Y, Wang S, Jiang F (2014) Tumor necrosis factor-related apoptosis-inducing ligand in vascular inflammation and atherosclerosis: a protector or culprit? Vascul Pharmacol 63(3):135-144. doi:10.1016/j.vph.2014.10.004

30. Collison A, Li J, Pereira de Siqueira A, Zhang J, Toop HD, Morris JC, Foster PS, Mattes J (2014) Tumor necrosis factorrelated apoptosis-inducing ligand regulates hallmark features of airways remodeling in allergic airways disease. Am J Respir Cell Mol Biol 51(1):86-93. doi:10.1165/rcmb.2013-0490OC

31. Tisato V, Garrovo C, Biffi S, Petrera F, Voltan R, Casciano F, Meroni G, Agnoletto C, Zauli G, Secchiero P (2014) Intranasal administration of recombinant TRAIL down-regulates CXCL-1/ $\mathrm{KC}$ in an ovalbumin-induced airway inflammation murine model. PLoS One 9(12):e115387. doi:10.1371/journal.pone.0115387

32. Faustino L, Fonseca DM, Florsheim EB, Resende RR, Lepique AP, Faquim-Mauro E, Gomes E, Silva JS, Yagita H, Russo M (2014) Tumor necrosis factor-related apoptosis-inducing ligand mediates the resolution of allergic airway inflammation induced by chronic allergen inhalation. Mucosal Immunol 7(5):11991208. doi: $10.1038 / \mathrm{mi} .2014 .9$

33. Zipp F, Aktas O (2006) The brain as a target of inflammation: common pathways link inflammatory and neurodegenerative diseases. Trends Neurosci 29(9):518-527. doi:10.1016/j.tins. 2006.07.006

34. Lo EH (2010) Degeneration and repair in central nervous system disease. Nat Med 16(11):1205-1209. doi:10.1038/nm.2226

35. Gronberg NV, Johansen FF, Kristiansen U, Hasseldam H (2013) Leukocyte infiltration in experimental stroke. J Neuroinflamm 10:115. doi:10.1186/1742-2094-10-115

36. Weinlich R, Brunner T, Amarante-Mendes GP (2010) Control of death receptor ligand activity by posttranslational modifications. Cell Mol Life Sci CMLS 67(10):1631-1642. doi:10.1007/ s00018-010-0289-7

37. Allen JE, El-Deiry WS (2012) Regulation of the human TRAIL gene. Cancer Biol Ther 13(12):1143-1151. doi:10.4161/cbt. 21354

38. Liabakk NB, Sundan A, Torp S, Aukrust P, Froland SS, Espevik $\mathrm{T}$ (2002) Development, characterization and use of monoclonal antibodies against sTRAIL: measurement of sTRAIL by ELISA. J Immunol Methods 259(1-2):119-128

39. Orlinick JR, Chao MV (1998) TNF-related ligands and their receptors. Cell Signal 10(8):543-551

40. Yerbes R, Palacios C, Lopez-Rivas A (2011) The therapeutic potential of TRAIL receptor signalling in cancer cells. Clin Transl Oncol 13(12):839-847. doi:10.1007/s12094-011-0744-4

41. Zauli G, Corallini F, Bossi F, Fischetti F, Durigutto P, Celeghini C, Tedesco F, Secchiero P (2007) Osteoprotegerin increases leukocyte adhesion to endothelial cells both in vitro and in vivo. Blood 110(2):536-543. doi:10.1182/blood-2007-01-068395

42. Secchiero P, Zauli G (2008) Letter by Secchiero and Zauli regarding article, "Osteoprotegerin inhibits vascular calcification without affecting atherosclerosis in $\operatorname{ldl}(-/-)$ mice. Circulation 118(2):e18. doi:10.1161/CIRCULATIONAHA.108. 765776 (author reply e19)

43. Secchiero P, Corallini F, Rimondi E, Chiaruttini C, di Iasio MG, Rustighi A, Del Sal G, Zauli G (2008) Activation of the p53 pathway down-regulates the osteoprotegerin expression and 
release by vascular endothelial cells. Blood 111(3):1287-1294. doi:10.1182/blood-2007-05-092031

44. Zauli G, Melloni E, Capitani S, Secchiero P (2009) Role of fulllength osteoprotegerin in tumor cell biology. Cell Mol Life Sci CMLS 66(5):841-851. doi:10.1007/s00018-008-8536-x

45. Corallini F, Bossi F, Gonelli A, Tripodo C, Castellino G, Mollnes TE, Tedesco F, Rizzi L, Trotta F, Zauli G, Secchiero P (2009) The soluble terminal complement complex (SC5b-9) upregulates osteoprotegerin expression and release by endothelial cells: implications in rheumatoid arthritis. Rheumatology 48(3):293-298. doi:10.1093/rheumatology/ken495

46. Corallini F, Celeghini C, Rimondi E, di Iasio MG, Gonelli A, Secchiero P, Zauli G (2011) Trail down-regulates the release of osteoprotegerin (OPG) by primary stromal cells. J Cell Physiol 226(9):2279-2286. doi:10.1002/jcp.22564

47. Rimondi E, di Iasio MG, Gonelli A, Celeghini C, Secchiero P, Zauli G (2012) Hydrogen sulfide down-regulates the expression and release of osteoprotegerin (OPG) by vascular endothelial cells. Invest New Drugs 30(4):1731-1735. doi:10.1007/s10637011-9675-8

48. Schneider P, Olson D, Tardivel A, Browning B, Lugovskoy A, Gong D, Dobles M, Hertig S, Hofmann K, Van Vlijmen H, Hsu YM, Burkly LC, Tschopp J, Zheng TS (2003) Identification of a new murine tumor necrosis factor receptor locus that contains two novel murine receptors for tumor necrosis factor-related apoptosis-inducing ligand (TRAIL). J Biol Chem 278(7):5444-5454. doi:10.1074/jbc.M210783200

49. Hellwig CT, Rehm M (2012) TRAIL signaling and synergy mechanisms used in TRAIL-based combination therapies. Mol Cancer Ther 11(1):3-13. doi:10.1158/1535-7163.MCT-11-0434

50. Bernardi S, Secchiero P, Zauli G (2012) State of art and recent developments of anti-cancer strategies based on TRAIL. Recent Pat Anti-Cancer Drug Discov 7(2):207-217

51. Almasan A, Ashkenazi A (2003) Apo2L/TRAIL: apoptosis signaling, biology, and potential for cancer therapy. Cytokine Growth Factor Rev 14(3-4):337-348

52. Pan G, Ni J, Wei YF, Yu G, Gentz R, Dixit VM (1997) An antagonist decoy receptor and a death domain-containing receptor for TRAIL. Science 277(5327):815-818

53. Sessler T, Healy S, Samali A, Szegezdi E (2013) Structural determinants of DISC function: new insights into death receptormediated apoptosis signalling. Pharmacol Ther 140(2):186-199. doi:10.1016/j.pharmthera.2013.06.009

54. Di Pietro R, Zauli G (2004) Emerging non-apoptotic functions of tumor necrosis factor-related apoptosis-inducing ligand (TRAIL)/Apo2L. J Cell Physiol 201(3):331-340. doi:10.1002/ jcp.20099

55. Zauli G, Sancilio S, Cataldi A, Sabatini N, Bosco D, Di Pietro R (2005) PI-3K/Akt and NF-kappaB/IkappaBalpha pathways are activated in Jurkat $\mathrm{T}$ cells in response to TRAIL treatment. J Cell Physiol 202(3):900-911. doi:10.1002/jcp.20202

56. Secchiero P, Gonelli A, Carnevale E, Milani D, Pandolfi A, Zella D, Zauli G (2003) TRAIL promotes the survival and proliferation of primary human vascular endothelial cells by activating the Akt and ERK pathways. Circulation 107(17):2250-2256. doi:10.1161/01.CIR.0000062702.60708.C4

57. Secchiero P, Zerbinati C, Rimondi E, Corallini F, Milani D, Grill V, Forti G, Capitani S, Zauli G (2004) TRAIL promotes the survival, migration and proliferation of vascular smooth muscle cells. Cell Mol Life Sci CMLS 61(15):1965-1974. doi:10.1007/s00018-004-4197-6

58. Secchiero P, Gonelli A, Mirandola P, Melloni E, Zamai L, Celeghini C, Milani D, Zauli G (2002) Tumor necrosis factorrelated apoptosis-inducing ligand induces monocytic maturation of leukemic and normal myeloid precursors through a caspase- dependent pathway. Blood 100(7):2421-2429. doi:10.1182/ blood-2002-01-0047

59. Zauli G, Rimondi E, Nicolin V, Melloni E, Celeghini C, Secchiero P (2004) TNF-related apoptosis-inducing ligand (TRAIL) blocks osteoclastic differentiation induced by RANKL plus M-CSF. Blood 104(7):2044-2050. doi:10.1182/blood-2004-031196

60. Rimondi E, Secchiero P, Quaroni A, Zerbinati C, Capitani S, Zauli G (2006) Involvement of TRAIL/TRAIL-receptors in human intestinal cell differentiation. J Cell Physiol 206(3):647-654. doi:10.1002/jcp.20512

61. Secchiero P, Melloni E, Corallini F, Beltrami AP, Alviano F, Milani D, D'Aurizio F, di Iasio MG, Cesselli D, Bagnara GP, Zauli G (2008) Tumor necrosis factor-related apoptosis-inducing ligand promotes migration of human bone marrow multipotent stromal cells. Stem Cells 26(11):2955-2963. doi:10. 1634/stemcells.2008-0512

62. Jaganathan BG, Tisato V, Vulliamy T, Dokal I, Marsh J, Dazzi F, Bonnet D (2010) Effects of MSC co-injection on the reconstitution of aplastic anemia patient following hematopoietic stem cell transplantation. Leukemia 24(10):1791-1795. doi:10. 1038/leu.2010

63. Zauli G, Rimondi E, Stea S, Baruffaldi F, Stebel M, Zerbinati C, Corallini F, Secchiero P (2008) TRAIL inhibits osteoclastic differentiation by counteracting RANKL-dependent p27Kip1 accumulation in pre-osteoclast precursors. J Cell Physiol 214(1):117-125. doi:10.1002/jcp.21165

64. Ashkenazi A (2008) Directing cancer cells to self-destruct with pro-apoptotic receptor agonists. Nat Rev Drug Discov 7(12):1001-1012. doi: $10.1038 / \mathrm{nrd} 2637$

65. Song JH, Tse MC, Bellail A, Phuphanich S, Khuri F, Kneteman NM, Hao C (2007) Lipid rafts and nonrafts mediate tumor necrosis factor related apoptosis-inducing ligand induced apoptotic and nonapoptotic signals in non small cell lung carcinoma cells. Cancer Res 67(14):6946-6955. doi:10.1158/00085472.CAN-06-3896

66. Hunter I, Nixon GF (2006) Spatial compartmentalization of tumor necrosis factor (TNF) receptor 1-dependent signaling pathways in human airway smooth muscle cells. Lipid rafts are essential for TNF-alpha-mediated activation of RhoA but dispensable for the activation of the NF-kappaB and MAPK pathways. J Biol Chem 281(45):34705-34715. doi:10.1074/jbc. M605738200

67. Psahoulia FH, Drosopoulos KG, Doubravska L, Andera L, Pintzas A (2007) Quercetin enhances TRAIL-mediated apoptosis in colon cancer cells by inducing the accumulation of death receptors in lipid rafts. Mol Cancer Ther 6(9):2591-2599. doi:10.1158/1535-7163.MCT-07-0001

68. Lim SC, Duong HQ, Choi JE, Lee TB, Kang JH, Oh SH, Han SI (2011) Lipid raft-dependent death receptor 5 (DR5) expression and activation are critical for ursodeoxycholic acid-induced apoptosis in gastric cancer cells. Carcinogenesis 32(5):723-731. doi:10.1093/carcin/bgr038

69. Bertsch U, Roder C, Kalthoff H, Trauzold A (2014) Compartmentalization of TNF-related apoptosis-inducing ligand (TRAIL) death receptor functions: emerging role of nuclear TRAIL-R2. Cell Death Dis 5:e1390. doi:10.1038/cddis.2014.351

70. Raychaudhuri S, Raychaudhuri SC (2014) Death ligand concentration and the membrane proximal signaling module regulate the type 1/type 2 choice in apoptotic death signaling. Syst Synth Biol 8(1):83-97. doi:10.1007/s11693-013-9124-4

71. Dorr J, Bechmann I, Waiczies S, Aktas O, Walczak H, Krammer PH, Nitsch R, Zipp F (2002) Lack of tumor necrosis factorrelated apoptosis-inducing ligand but presence of its receptors in the human brain. J Neurosci 22(4):RC209 
72. Cannella B, Gaupp S, Omari KM, Raine CS (2007) Multiple sclerosis: death receptor expression and oligodendrocyte apoptosis in established lesions. J Neuroimmunol 188(1-2):128-137. doi:10.1016/j.jneuroim.2007.05.018

73. Nitsch R, Bechmann I, Deisz RA, Haas D, Lehmann TN, Wendling U, Zipp F (2000) Human brain-cell death induced by tumour-necrosis-factor-related apoptosis-inducing ligand (TRAIL). Lancet 356(9232):827-828. doi:10.1016/S01406736(00)02659-3

74. Aktas O, Schulze-Topphoff U, Zipp F (2007) The role of TRAIL/TRAIL receptors in central nervous system pathology. Front Biosci 12:2912-2921

75. Querfurth HW, LaFerla FM (2010) Alzheimer's disease. N Engl J Med 362(4):329-344. doi:10.1056/NEJMra0909142

76. Noble W, Hanger DP, Miller CC, Lovestone S (2013) The importance of tau phosphorylation for neurodegenerative diseases. Front Neurol 4:83. doi:10.3389/fneur.2013.00083

77. Wyss-Coray $\mathrm{T}$ (2006) Inflammation in Alzheimer disease: driving force, bystander or beneficial response? Nat Med 12(9):1005-1015. doi:10.1038/nm1484

78. Uberti D, Cantarella G, Facchetti F, Cafici A, Grasso G, Bernardini R, Memo M (2004) TRAIL is expressed in the brain cells of Alzheimer's disease patients. NeuroReport 15(4):579-581

79. Cantarella G, Uberti D, Carsana T, Lombardo G, Bernardini R, Memo M (2003) Neutralization of TRAIL death pathway protects human neuronal cell line from beta-amyloid toxicity. Cell Death Differ 10(1):134-141. doi:10.1038/sj.cdd.4401143

80. Uberti D, Ferrari-Toninelli G, Bonini SA, Sarnico I, Benarese M, Pizzi M, Benussi L, Ghidoni R, Binetti G, Spano P, Facchetti F, Memo M (2007) Blockade of the tumor necrosis factor-related apoptosis inducing ligand death receptor DR5 prevents beta-amyloid neurotoxicity. Neuropsychopharmacology 32(4):872-880. doi:10.1038/sj.npp.1301185

81. Fossati S, Ghiso J, Rostagno A (2012) TRAIL death receptors DR4 and DR5 mediate cerebral microvascular endothelial cell apoptosis induced by oligomeric Alzheimer's A $\beta$. Cell Death Dis 3:e321. doi:10.1038/cddis.2012.55

82. Cantarella G, Di Benedetto G, Puzzo D, Privitera L, Loreto C, Saccone S, Giunta S, Palmeri A, Bernardini R (2015) Neutralization of TNFSF10 ameliorates functional outcome in a murine model of Alzheimer's disease. Brain 138(Pt 1):203-216. doi:10. 1093/brain/awu318

83. Genc S, Egrilmez MY, Yaka E, Cavdar Z, Iyilikci L, Yener G, Genc K (2009) TNF-related apoptosis-inducing ligand level in Alzheimer's disease. Neurol Sci 30(3):263-267. doi:10.1007/ s10072-009-0047-5

84. Frenkel D (2015) A new TRAIL in Alzheimer's disease therapy. Brain 138(Pt 1):8-10. doi:10.1093/brain/awu334

85. Disanto G, Morahan JM, Ramagopalan SV (2012) Multiple sclerosis: risk factors and their interactions. CNS Neurol Disord Drug Targets 11(5):545-555

86. Friese MA, Schattling B, Fugger L (2014) Mechanisms of neurodegeneration and axonal dysfunction in multiple sclerosis. Nat Rev Neurol 10(4):225-238. doi:10.1038/nrneurol.2014.37

87. Hemmer B, Kerschensteiner M, Korn T (2015) Role of the innate and adaptive immune responses in the course of multiple sclerosis. Lancet Neurol 14(4):406-419. doi:10.1016/S14744422(14)70305-9

88. Mahad DH, Trapp BD, Lassmann H (2015) Pathological mechanisms in progressive multiple sclerosis. Lancet Neurol 14(2):183-193. doi:10.1016/S1474-4422(14)70256-X

89. Ben-Nun A, Kaushansky N, Kawakami N, Krishnamoorthy G, Berer K, Liblau R, Hohlfeld R, Wekerle H (2014) From classic to spontaneous and humanized models of multiple sclerosis: impact on understanding pathogenesis and drug development. J Autoimmun 54:33-50. doi:10.1016/j.jaut.2014.06.004
90. Hilliard B, Wilmen A, Seidel C, Liu TS, Goke R, Chen Y (2001) Roles of TNF-related apoptosis-inducing ligand in experimental autoimmune encephalomyelitis. J Immunol 166(2):1314-1319

91. Cretney E, McQualter JL, Kayagaki N, Yagita H, Bernard CC, Grewal IS, Ashkenazi A, Smyth MJ (2005) TNF-related apoptosis-inducing ligand (TRAIL)/Apo2L suppresses experimental autoimmune encephalomyelitis in mice. Immunol Cell Biol 83(5):511-519. doi:10.1111/j.1440-1711.2005.01358.x

92. Lunemann JD, Waiczies S, Ehrlich S, Wendling U, Seeger B, Kamradt T, Zipp F (2002) Death ligand TRAIL induces no apoptosis but inhibits activation of human (auto)antigen-specific T cells. J Immunol 168(10):4881-4888

93. Ikeda T, Hirata S, Fukushima S, Matsunaga Y, Ito T, Uchino M, Nishimura Y, Senju S (2010) Dual effects of TRAIL in suppression of autoimmunity: the inhibition of Th1 cells and the promotion of regulatory T cells. J Immunol 185(9):5259-5267. doi:10.4049/jimmunol.0902797

94. Aktas O, Smorodchenko A, Brocke S, Infante-Duarte C, Schulze Topphoff U, Vogt J, Prozorovski T, Meier S, Osmanova V, Pohl E, Bechmann I, Nitsch R, Zipp F (2005) Neuronal damage in autoimmune neuroinflammation mediated by the death ligand TRAIL. Neuron 46(3):421-432. doi:10.1016/j.neuron.2005.03. 018

95. Prinz-Hadad H, Mizrachi T, Irony-Tur-Sinai M, Prigozhina TB, Aronin A, Brenner T, Dranitzki-Elhalel M (2013) Amelioration of autoimmune neuroinflammation by the fusion molecule Fn14.TRAIL. J Neuroinflamm 10:36. doi:10.1186/1742-209410-36

96. Yellayi S, Hilliard B, Ghazanfar M, Tsingalia A, Nantz MH, Bollinger L, de Kok-Mercado F, Hecker JG (2011) A single intrathecal injection of DNA and an asymmetric cationic lipid as lipoplexes ameliorates experimental autoimmune encephalomyelitis. Mol Pharm 8(5):1980-1984. doi:10.1021/ mp2002413

97. Moreno M, Saenz-Cuesta M, Castillo J, Canto E, Negrotto L, Vidal-Jordana A, Montalban X, Comabella M (2013) Circulating levels of soluble apoptosis-related molecules in patients with multiple sclerosis. J Neuroimmunol 263(1-2):152-154. doi:10. 1016/j.jneuroim.2013.07.013

98. Tawdy MH, Abd El Nasser MM, Abd El Shafy SS, Nada MA, El Sirafy MN, Magd AH (2014) Role of serum TRAIL level and TRAIL apoptosis gene expression in multiple sclerosis and relation to brain atrophy. J Clin Neurosci 21(9):1606-1611. doi:10.1016/j.jocn.2013.11.056

99. Wandinger KP, Lunemann JD, Wengert O, Bellmann-Strobl J, Aktas O, Weber A, Grundstrom E, Ehrlich S, Wernecke KD, Volk HD, Zipp F (2003) TNF-related apoptosis inducing ligand (TRAIL) as a potential response marker for interferon-beta treatment in multiple sclerosis. Lancet 361(9374):2036-2043. doi:10.1016/S0140-6736(03)13641-0

100. Zula JA, Green HC, Ransohoff RM, Rudick RA, Stark GR, van Boxel-Dezaire AH (2011) The role of cell type-specific responses in IFN-beta therapy of multiple sclerosis. Proc Natl Acad Sci USA 108(49):19689-19694. doi:10.1073/pnas. 1117347108

101. Weber A, Wandinger KP, Mueller W, Aktas O, Wengert O, Grundstrom E, Ehrlich S, Windemuth C, Kuhlmann T, Wienker T, Bruck W, Zipp F (2004) Identification and functional characterization of a highly polymorphic region in the human TRAIL promoter in multiple sclerosis. J Neuroimmunol 149(1-2):195-201. doi:10.1016/j.jneuroim.2003.12.014

102. Kikuchi S, Miyagishi R, Fukazawa T, Yabe I, Miyazaki Y, Sasaki H (2005) TNF-related apoptosis inducing ligand (TRAIL) gene polymorphism in Japanese patients with multiple sclerosis. J Neuroimmunol 167(1-2):170-174. doi:10.1016/j. jneuroim.2005.06.021 
103. Lopez-Gomez C, Fernandez O, Garcia-Leon JA, Pinto-Medel MJ, Oliver-Martos B, Ortega-Pinazo J, Suardiaz M, GarciaTrujillo L, Guijarro-Castro C, Benito-Leon J, Prat I, Varade J, Alvarez-Lafuente R, Urcelay E, Leyva L (2011) TRAIL/TRAIL receptor system and susceptibility to multiple sclerosis. PLoS One 6(7):e21766. doi:10.1371/journal.pone.0021766

104. Lopez-Gomez C, Oliver-Martos B, Pinto-Medel MJ, Suardiaz M, Reyes-Garrido V, Urbaneja P, Fernandez O, Leyva L (2015) TRAIL and TRAIL receptors splice variants during long-term interferon beta treatment of patients with multiple sclerosis: evaluation as biomarkers for therapeutic response. J Neurol Neurosurg Psychiatry. doi:10.1136/jnnp-2014-309932

105. Elbirt D, Mahlab-Guri K, Bezalel-Rosenberg S, Gill H, Attali M, Asher I (2015) HIV-associated neurocognitive disorders (HAND). Isr Med Assoc J 17(1):54-59

106. Ryan LA, Peng H, Erichsen DA, Huang Y, Persidsky Y, Zhou Y, Gendelman HE, Zheng J (2004) TNF-related apoptosis-inducing ligand mediates human neuronal apoptosis: links to HIV1-associated dementia. J Neuroimmunol 148(1-2):127-139. doi:10.1016/j.jneuroim.2003.11.019

107. Huang Y, Walstrom A, Zhang L, Zhao Y, Cui M, Ye L, Zheng JC (2009) Type I interferons and interferon regulatory factors regulate TNF-related apoptosis-inducing ligand (TRAIL) in HIV-1-infected macrophages. PLoS One 4(4):e5397. doi:10. 1371/journal.pone.0005397

108. Lu S, Peng H, Wang L, Vasish S, Zhang Y, Gao W, Wu W, Liao M, Wang M, Tang H, Li W, Li W, Li Z, Zhou J, Zhang Z, Li L (2013) Elevated specific peripheral cytokines found in major depressive disorder patients with childhood trauma exposure: a cytokine antibody array analysis. Compr Psychiatry 54(7):953-961. doi:10.1016/j.comppsych.2013.03.026

109. Levandowski ML, Viola TW, Wearick-Silva LE, Wieck A, Tractenberg SG, Brietzke E, Bauer ME, Teixeira AL, GrassiOliveira R (2014) Early life stress and tumor necrosis factor superfamily in crack cocaine withdrawal. J Psychiatr Res 53:180-186. doi:10.1016/j.jpsychires.2014.02.017

110. Xing C, Arai K, Lo EH, Hommel M (2012) Pathophysiologic cascades in ischemic stroke. Int J Stroke 7(5):378-385. doi:10. 1111/j.1747-4949.2012.00839.x

111. Shichita T, Ito M, Yoshimura A (2014) Post-ischemic inflammation regulates neural damage and protection. Front Cell Neurosci 8:319. doi:10.3389/fncel.2014.00319

112. Prestigiacomo CJ, Kim SC, Connolly ES Jr, Liao H, Yan SF, Pinsky DJ (1999) CD18-mediated neutrophil recruitment contributes to the pathogenesis of reperfused but not nonreperfused stroke. Stroke 30(5):1110-1117

113. Mabuchi T, Kitagawa K, Ohtsuki T, Kuwabara K, Yagita Y, Yanagihara T, Hori M, Matsumoto M (2000) Contribution of microglia/macrophages to expansion of infarction and response of oligodendrocytes after focal cerebral ischemia in rats. Stroke 31(7):1735-1743

114. Lehnardt S, Lehmann S, Kaul D, Tschimmel K, Hoffmann O, Cho S, Krueger C, Nitsch R, Meisel A, Weber JR (2007) Tolllike receptor 2 mediates CNS injury in focal cerebral ischemia. J Neuroimmunol 190(1-2):28-33. doi:10.1016/j.jneuroim.2007. 07.023

115. Martin-Villalba A, Herr I, Jeremias I, Hahne M, Brandt R, Vogel J, Schenkel J, Herdegen T, Debatin KM (1999) CD95 ligand (Fas-L/APO-1L) and tumor necrosis factor-related apoptosis-inducing ligand mediate ischemia-induced apoptosis in neurons. J Neurosci 19(10):3809-3817

116. Martin-Villalba A, Hahne M, Kleber S, Vogel J, Falk W, Schenkel J, Krammer PH (2001) Therapeutic neutralization of CD95-ligand and TNF attenuates brain damage in stroke. Cell Death Differ 8(7):679-686. doi:10.1038/sj.cdd.4400882

117. Cui M, Wang L, Liang X, Ma X, Liu Y, Yang M, Liu K, Wei X, Zhou Z, Chen YH, Sun W (2010) Blocking TRAIL-DR5 signaling with soluble DR5 reduces delayed neuronal damage after transient global cerebral ischemia. Neurobiol Dis 39(2):138147. doi: $10.1016 /$ j.nbd.2010.03.018

118. Huang Z, Song L, Wang C, Liu JQ, Chen C (2011) Hypoxiaischemia upregulates TRAIL and TRAIL receptors in the immature rat brain. Dev Neurosci 33(6):519-530. doi:10.1159/ 000334475

119. Cantarella G, Pignataro G, Di Benedetto G, Anzilotti S, Vinciguerra A, Cuomo O, Di Renzo GF, Parenti C, Annunziato L, Bernardini R (2014) Ischemic tolerance modulates TRAIL expression and its receptors and generates a neuroprotected phenotype. Cell Death Dis 5:e1331. doi:10.1038/cddis.2014.286

120. Panneerselvam M, Patel PM, Roth DM, Kidd MW, Chin-Lee B, Head BP, Niesman IR, Inoue S, Patel HH, Davis DP (2011) Role of decoy molecules in neuronal ischemic preconditioning. Life Sci 88(15-16):670-674. doi:10.1016/j.lfs.2011.02.004

121. Sarchielli P, Nardi K, Chiasserini D, Eusebi P, Tantucci M, Di Piero V, Altieri M, Marini C, Russo T, Silvestrini M, Paolino I, Calabresi P, Parnetti L (2013) Immunological profile of silent brain infarction and lacunar stroke. PLoS One 8(7):e68428. doi:10.1371/journal.pone.0068428

122. Kang YH, Park MG, Noh KH, Park HR, Lee HW, Son SM, Park KP (2015) Low serum TNF-related apoptosis-inducing ligand (TRAIL) levels are associated with acute ischemic stroke severity. Atherosclerosis 240(1):228-233. doi:10.1016/j.atherosclerosis. 2015.03.028 